\title{
Velocity distribution characteristics within the non-submerged sea buckthorn plant flexible dam*
}

\author{
Fang-She Yang ${ }^{\dagger}$, Hong-Min Zhang, Chen Han and Hao Wang \\ School of Urban and Environmental Science, Northwest University, \\ Xi'an, Shaanxi Province, China \\ †E-mail: yangfangshe978@163.com
}

\begin{abstract}
The seabuckthorn plant flexible dam (The SPFD) is a new type of ecological engineering, which can efficaciously control soil erosion and capture sediment in the Pisha sandstone gully within Loess Plateau of China. The seabuckthorn plant can resist flow due mainly to slowing velocity, and thus reduce the flow scour stress and the sediment carrying capacity. It is therefore necessary to analyze the flow velocity distribution within the SPFD. The results showed that: i) the SPFD has a significant effect on the both lengthwise and transverse directions; ii) the average transect velocity reduced progressively in longitudinal direction, and the width-averaged velocity in the same depth at each transect reduced along the lengthways direction; iii) the velocity distribution at transect shows the reversetongue pattern that is quite different from that of general river. This study can lay a significant foundation for further study on the vegetation resistance and its formulation as well as function.
\end{abstract}

Keywords: The Sea Buckthorn Plant Flexible Dam (The SPFD); Velocity Distribution Characteristics; Flow Resistance; Retardation Effect; Field Flow Experiment.

\section{Introduction}

Great attention has been paid to study on soil and water conservation with the deterioration environment and the intensity of soil loss (Xiao et al., 2014; Hui et al., 2010). The Pisha Sandstone covers an area of $1.2 \mathrm{~km} 2$, soil erosion of which is the most serious within Loess Plateau of China. It is located in the joint region of Shanxi province, Shaanxi Province, and Inner Mongolia autonomous region of China. The sediment deposition occurred in the lower Yellow river is mainly because of the area. Based on the water yield and sediment transport behaviors

*This research is supported by NNSF project of China (No. 51279163), key sci-tech innovation team program of Shaanxi province (2014KCT-27), and NNSF of Shaanxi province (2010JQ5003). We are grateful to Professors Junjie Ma, Mingming Cao, Jinxi Song, and Huaien $\mathrm{Li}$ for their helpful suggestions during the course of writing manuscript. We also thank the two anonymous reviewers for their advices and comments. 
of the Pisha sandstone gully, the sea buckthorn plant flexible dam (the SPFD) a peculiar ecological engineering was proposed by $\mathrm{Bi}$ (Bi and $\mathrm{Li}, 2003$; $\mathrm{Bi}$ et al., 2003 ) in 1996, which is composed of the sea buckthorn plant and can effectively prevent soil loss in the small catchment gully.

To analyze the effect of the SPFD on flow, we conducted an experiment on flow behaviors within the SPFD at the field test base located in Mei county of Shaanxi Province of China. According to the experimental data, the longitudinal and transverse velocity distribution and their variation were analyzed under various design parameters with non-submerged sea buckthorn plant. Moreover, the resistance of the SPFD to flow was also discussed, which has a significant value for further study on the sea buckthorn's effect on flow.

\subsection{Experimental design and measurement methods}

The soil of the test base is yellow clay soil. The soil contains $8.18-34.34 \mathrm{~g} \cdot \mathrm{kg}-1$ organic matter with 7.15-8.5 PH. In this experiment, the five SPFD test beds were designed, numbered by 1\#, 2\#, 3\#, 4\#, and 5\#. Amongst them, the fifth test bed (i.e. 5\#) was used as the control one. The SPFD is composed of real sea buckthorn, which is planted in the stagger arrangement. The slope of each test bed is 4\%o. The plantation parameters of the SPFDs within the test beds are shown in Table 1.

Table 1. Plantation parameters of the SPFDs (May, 2016).

\begin{tabular}{ccccccc}
\hline Test beds & $\begin{array}{c}\text { Length } \\
(\mathrm{m})\end{array}$ & $\begin{array}{c}\text { Width } \\
(\mathrm{cm})\end{array}$ & $\begin{array}{c}\text { Spacing Between } \\
\text { plants }(\mathrm{cm})\end{array}$ & $\begin{array}{c}\text { Row spacing } \\
(\mathrm{cm})\end{array}$ & $\begin{array}{c}\text { Number } \\
\text { of trees } \\
(\text { tree })\end{array}$ & $\begin{array}{c}\text { Planting } \\
\text { Density } \\
\left(\text { trees } \cdot \mathrm{m}^{-2}\right)\end{array}$ \\
\hline $1 \#$ & 7.0 & 90 & 10 & 100 & 98 & 18.8 \\
$2 \#$ & 5.0 & 90 & 10 & 100 & 65 & 18.9 \\
$3 \#$ & 6.0 & 90 & 10 & 150 & 58 & 11.5 \\
$4 \#$ & 4.5 & 90 & 10 & 100 & 56 & 16.5 \\
\hline
\end{tabular}

\subsection{Experimental facilities and layout}

The facilities of the test base comprise tank, gauge, stilling pool, test beds and draining ditch. When starting, the water in the tank start to flow into the gauge, then into the stilling pool, finally into the SPFD test bed stably. The flow discharge was kept stable by means of the pump. The discharge is measured by the gauge. The layout of the test facilities is as following in Figure 1. 


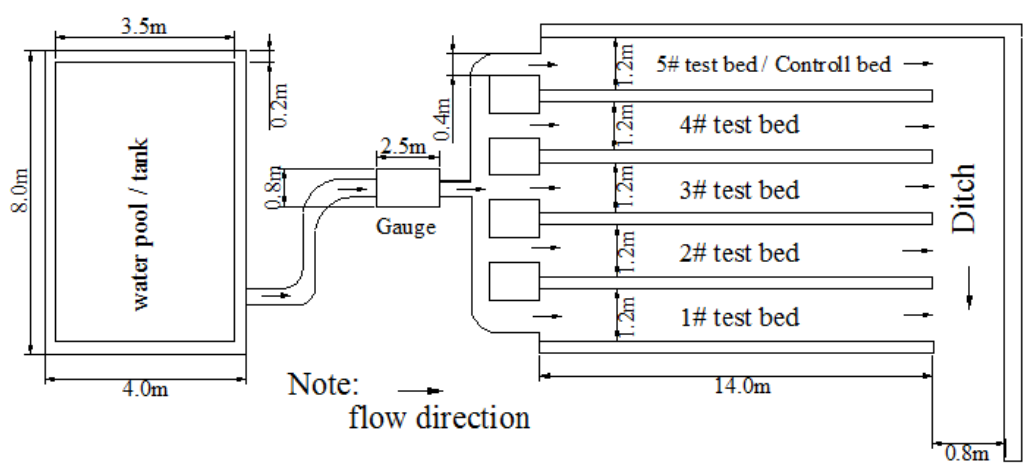

Fig. 1. Layout of the experimental facilities

\subsection{Experimental methods}

Water by pump flowed steadily into the gauge, stilling basin, and then into the sea buckthorn plant flexible dam via diverting trench. The formation of each test bed is trapezoidal. The flow is under non-submerged state during the test. Measuring sections were deployed at an interval of $1.0 \mathrm{~m}$ starting from $0.5 \mathrm{~m}$ distanced from the entrance of each test bed, excluding the $3 \#$ test bed. The measuring sections were planned at an interval of $1.6 \mathrm{~m}$ within the $3 \#$ test bed starting from $0.5 \mathrm{~m}$ behind the inlet. Additionally, the two measuring transects were set proximately $20 \mathrm{~cm}$ before and after the second sea buckthorn row within the $3 \#$ test bed. The measurements of water depth and velocity were conducted at $2 \mathrm{~cm}$, $4 \mathrm{~cm}, 6 \mathrm{~cm}, 8 \mathrm{~cm}$, and $10 \mathrm{~cm}$ positions above the ground at each measurement transect. Water depth was measured using the $50 \mathrm{~cm}$ long steel ruler. Flow velocity was measured using the ZLY-I automatic instrument made by Ruidi hightech corporation of Nanjing city of China. The instrument is connected with computer, the data set was recorded by its software, and the corresponding text file was simultaneously created on the computer. The four sensors were installed at each measurement transect in tantamount distance away from the left side wall. The point velocities of five points were measured at each vertical direction within each measurement transect, at the depth of $2 \mathrm{~cm}, 4 \mathrm{~cm}, 6 \mathrm{~cm}, 8 \mathrm{~cm}$, and $10 \mathrm{~cm}$, respectively. The measurement time is half a minute and the measurement time step is $3 \mathrm{~s}$, and the water depth is recorded concurrently. The installment scheme of sensors is shown in Figure 2. 


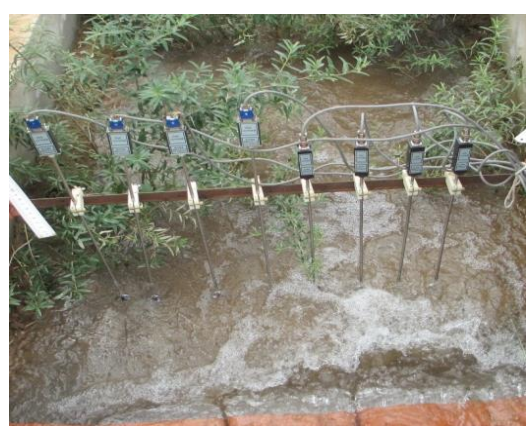

Fig. 2. Scheme of deployed sensors

In addition, at the beginning of the tests, the growth status of all the SPFDS needed to be investigated, because the sea buckthorn plant growth has an important impact on water flow under various growing stage. The growth parameters of the SFDs were outlined in Table 2.

Table 2. Growth parameters of all the SPFDs

\begin{tabular}{cccc}
\hline No. & Height $(\mathrm{cm})$ & Mean canopy $(\mathrm{cm})$ & Basal diameter $(\mathrm{cm})$ \\
$1 \#$ & 42.5 & 25.6 & 0.45 \\
$2 \#$ & 44.3 & 28.2 & 0.49 \\
$3 \#$ & 43.2 & 23.4 & 0.45 \\
$4 \#$ & 40.5 & 21.7 & 0.44 \\
\hline
\end{tabular}

\section{Results and Discussions}

\subsection{Vertical velocity distribution and lengthways variation of transect- averaged velocity at certain depth within the SPFD}

The vertical velocity distribution within each SPFD is roughly similar based on test data. Take here the $2 \#$ SPFD as an example. Figure 3 indicates that the vertical velocity distribution at seven typical measuring sections for the $2 \#$ test bed under the design discharge. The measurement sections are respectively at $0.6 \mathrm{~m}$, $1.4 \mathrm{~m}, 2.2 \mathrm{~m}, 3.0 \mathrm{~m}, 3.8 \mathrm{~m}, 4.6 \mathrm{~m}$, and $5.4 \mathrm{~m}$. As can be seen from Figure 3 that the sequence of average velocity of all layers V2>V3>V4>V5>V1 (") " denotes "greater"). The minimum is V1 measured at $2 \mathrm{~cm}$ above the bed, which is because of the resistance of the test bed to flow. The maximum is V2, measured at $4 \mathrm{~cm}$ near the bed, which is ascribed to the less resistance of test bed to flow at this depth. In addition, during the test, we found that vegetation near the bed has only trunk, but less side stems, and then above the $4 \mathrm{~cm}$ has more stems and leaves along with gradually extending canopy. The resistance to flow increases therefore successively from the $4 \mathrm{~cm}$ to up along the seabuckthorn tree, which leads to gradually decreasing velocity from bottom to top along the seabuckthorn 
tree. It can be seen that velocity distribution shows ' $\mathrm{S}$ ' form along vertical direction, which is in good accordance with research results conducted by other researcher with other vegetation (Shi and Li, 2003; Huang et al., 1999; Huai et al., 2009).

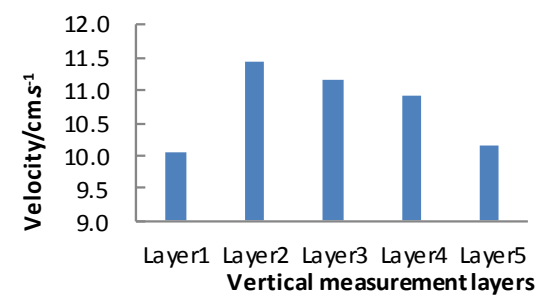

Fig. 3. Velocity distribution in vertical direction of the 2 \# test bed.

Due to the vegetation, the flow area is decreased at transect within the test bed. There occurred water blocking phenomenon because of the resistance of the vegetation. The vertical velocity distribution is susceptible to the growth, stem and leaves distribution, and row arrangement of the sea buckthorn, which is responsible for the complicated flow variation under the condition of the flexible plant (Zhang et al., 2014). The width-averaged velocity longitudinal variation is showed in Figure 4 at various depths within the 2\# test bed.

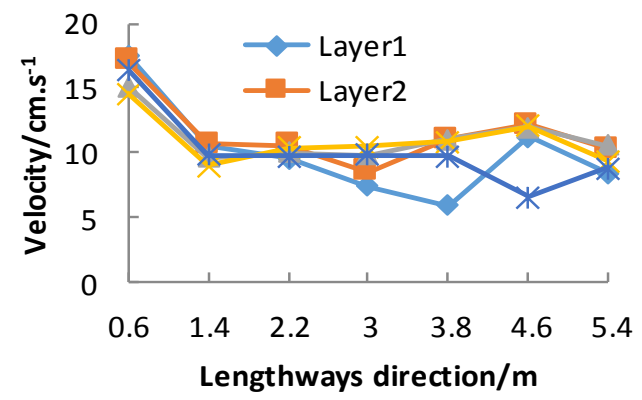

Fig. 4. Longitudinal variation of width-averaged velocity at various depths (2 \# test bed).

As shown in Figure 4, after water flows completely into the SPFD, the flow velocity has the same variable tendency for whichever layer, i.e. the velocity reduced dramatically $(0.16 \mathrm{~m} / \mathrm{s}$ to $0.1 \mathrm{~m} / \mathrm{s})$ at the 2 nd sea buckthorn row, and then the velocity within the SPFD progressively reduced up to being stable, and finally the velocity increased gradually at the end of the SPFD (i.e. the 5th and 6th rows) due to less resistance. The layers 1 and 5 have greater velocity oscillation because the two layers' positions are peculiar. The velocity of the layer 1 i.e. that near the bed, is of great variation due to the SPFD and the test bed roughness. 
The velocity of the layer 5, i.e. that near the flow surface, is also obviously variable due to the effect of the resilience and rigidity of the canopy, stem, and leaves.

Generally speaking, the vertical flow velocity profile distribution is in agreement with the parabolic functional distribution without the vegetation, that is, the velocity decreases gradually from water surface to bed bottom. With the vegetation, however, the vertical velocity distribution showed the ' $S$ ' form, and the maximum velocity seems approximately at the 0.6 -fold whole vertical water depth. The found law is well consistent with the research results conducted by some researchers using the other types of plant (Huai et al., 2009; Chen and Kao, 2011).

\subsection{The velocity distribution at transect within the SPFD}

According to the experimental data, the velocity distribution at transaction is roughly the same within different SPFD. Taking the $2 \#$ test bed as a case, the velocity distribution at various transects is showed in Figure 5 within the 2\# test bed. In terms of hydraulics and river dynamics theory, the velocity distribution at transect conforms theoretically to the "flow tongue" pattern on the river channel/ gully without vegetation. The cross-sectional velocity distribution showed the wavy form like serrate or "zigzag" picture. The main cause is that the resistance of the sea buckthorn rows to flow when water flowing into the sea buckthorn row leads to the distribution form. Further, according to the minimum energy dissipation theory by Chi-Ta YANG (Yang, 1992), flow would be forced to pass the gap between the two neighboring sea buckthorn trees. The flow velocity at $\mathrm{C} 1$ transect is obviously greater than that at the other one. As a result of the limitation of experimental condition, no more measurement points were deployed at each transect, which made data slightly less.

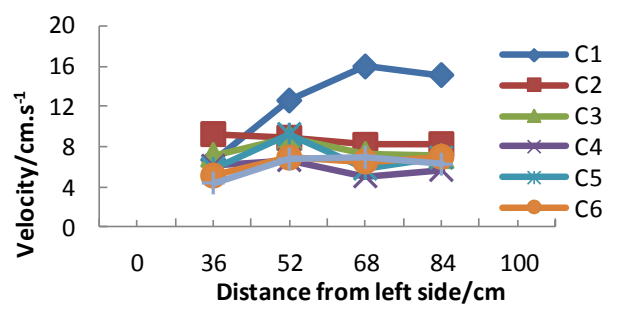

Fig. 5. Flow velocity distribution of different cross-sections (2 \# test bed).

\section{Conclusions}

Based on the above analyses, the conclusions were drawn as following. (i) The sea buckthorn plant is bound to resist flow and increase the flow resistance while 
water is flowing through the sea buckthorn rows, after the SPFD was planted. (ii) The SPFD strikingly altered the cross-sectional velocity distribution, and then reduced flow velocity, and therefore diminished sediment carrying capacity. (iii) The vertical velocity distribution showed the "S" form within the SPFD. (iv)The sediment retention capacity of the SPFD is dependent on the dam length, plantation arrangement, plantation density, etc. (V) Due to the field limitation, no more measuring points were set at each transect, which we will consider in our further study to acquire more data.

\section{References}

1. P. Q. Xiao, W. Y. Yao, H. Liu. Research advance and control methods in soil and water loss in the Pisha Sandstone area. Journal of Yellow River, 2014, 36(10): 92-94. (in Chinese)

2. E. Q. Hui, X. E. Hu, C. B. Jiang, et al. A study of drag coefficient related with vegetation based on the flume experiment. Journal of Hydrodynamics, Ser. B, 2010, 22(3): 329-337. (in Chinese)

3. C. F. Bi, G. F. Li. Field protype test research on the sea buckthorn plant flexible dam on sediment retention within the Pisha Sandstone area. Journal of Global sea buckthorn research and development, 2003, (1): 6-12. (in Chinese)

4. C. F. Bi, F. G. Wang, G. F. Li, et al. Field experiment on sediment trapping of the sea buckthorn flexible dam in the soft rock region. Journal of sediment research, 2003, (2): 14-25. (in Chinese)

5. Z. Shi, Y. H. Li. Experi mental studies of mean velocity profiles in vegetated river flow. Journal of ShangHai JiaoTong University, 2003, 37(8):12541260. (in Chinese)

6. B. S. Huang, G. W. Lai, et al. Experimental study on the effects of planting trees on the riffle area on flood running. Journal of Hydrodynamics, 1999, 14(4):468-474. (in Chinese)

7. W. X. Huai, L. Zhao, et al. Experimental analysis of vertical profiles of stream-wise velocities in flows through vegetation with PIV. Journal of Experiments in Fluid Mechanics, 2009, 23(1): 26-30. (in Chinese)

8. Y. H., Zhang, X. J. Lai, J. H. Jiang. Advances in the plant effect on water flow and sediment transportation. Journal of wetland science, 2014, 12(5): 669-676.

9. Y. C. Chen, S. P. Kao. Velocity distribution in open channels with submerged aquatic plant. Hydrological Processes, 2011, 25(13): 2009-2017.

10. C. T. Yang. Force, energy, entropy and energy dissipation rate. Journal of sediment information, 1992, (1):12-22. 